\title{
Immunohistochemical localization of chorionic gonadotrophin on baboon placenta, dispersed trophoblast cells and those derived from blastocysts grown in vitro
}

\author{
C. S. Bambra and R. Tarara \\ Institute of Primate Research, National Museums of Kenya, Box 24481, Karen, Nairobi, Kenya
}

\begin{abstract}
Summary. An immunohistochemical technique using a high specificity antiserum against baboon CG was used to demonstrate the presence of a CG-like material on: (1) fixed baboon placental sections collected between 31 and 39 days of gestation, (2) trophoblast monolayers derived from hatched embryos grown in vitro for 15 days and (3) trophoblast cells derived from cells dispersed from placentae collected between Days 31 and 39 of pregnancy. A specific radioimmunoassay was used to detect concentrations of baboon $C G$ in daily spent medium. Immunohistochemical studies showed that material cross-reacting with $\mathrm{CG}$ was present on all the three sources of trophoblast. The embryos secreted CG from attachment onwards and immunoactive CG was measurable in daily spent medium collected from placenta-derived trophoblast cultures. It is concluded that baboon CG is localized in the syncytiotrophoblast of fixed placental sections and cellular trophoblast derived from cultured embryos and placental cells.
\end{abstract}

Kel'w'ords: baboon; trophoblast; chorionic gonadotrophin; immunochemistry

\section{Introduction}

Chorionic gonadotrophin (CG) is synthesized and secreted by trophoblast cells during human pregnancy. The precise temporal appearance of this hormone in women is not known and estimates for the time of its first appearance range between 6 and 11 days after ovulation (Saxena et al., 1974; Catt et al., 1975; Landesman \& Saxena, 1976; Ahmed \& Klopper, 1983; Hay, 1985). Most primates are known to produce a CG-like material during pregnancy (Hearn, 1980; Hodgen, 1980) and rhesus monkey morulae and blastocysts maintained in vitro have been shown to secrete a substance capable of inducing luteinization of monkey granulosa cells (Batta \& Channing, 1979). In-vitro cultures of baboon (Pope et al., 1980) and marmoset (Summers et al., 1987) trophoblast have been shown to secrete measurable quantities of $\mathrm{CG}$ as detected by radioimmunoassay after blastocyst attachment. Evidence of the presence of a CG-like material in preimplantation embryos of several non-primate species such as the mouse and rabbit is also available (Haour \& Saxena, 1974; Wiley, 1974; Asch et al., 1978, 1979; Varma et al., 1979).

Histochemical and immunofluorescent techniques coupled with light- or electron-microscopy have shown that hCG is localized predominantly in the human syncytiotrophoblast (Beck et al., 1969; Hamanaka et al., 1971; Genabacev et al., 1972; Genabacev \& Sulovic, 1975). However, other workers have shown that human CG can be localized on the cytotrophoblast (Thiede \& Choate, 1963; Loke et al., 1972; Tojo et al., 1974) and these results have been mostly obtained in studies utilizing human trophoblast cultured in vitro. The baboon produces a CG similar to hCG during pregnancy (Bambra, 1987) and the studies reported herein were carried out to determine its cellular origin on fixed placental sections, placental trophoblast cells cultured in vitro and trophoblast derived from embryos grown in vitro. 


\section{Materials and Methods}

Placentae. Placental tissue was obtained from time-mated pregnant baboons at 31-39 days of gestation and fixed in acetone. Blocks were cut from these placentae in a standardized manner, embedded in paraffin wax (MP 56 C) and sectioned at $5 \mu \mathrm{m}$. Serial sections were prepared for staining by immunohistochemical methods to determine the distribution of $\mathrm{CG}$.

Embryo recovery. The procedure was exactly that described by Pope et al. (1980). Essentially, an Isaac's endometrial cell sampler, modified to permit bidirectional flow of tissue culture medium, was inserted across the undilated cervix of the anaesthetized female baboon an estimated 6 days after ovulation, as determined by loss of sexual skin turgescence. Then $15 \mathrm{ml}$ ovum culture medium (Flow Laboratories, Irvine, UK) were flushed through the cell sampler, collected in a sterile conical tube, decanted into a $10 \times 35 \mathrm{~mm}$ Petri dish and examined for embryos with a Leitz stereomicroscope. Recovered embryos which were at the hatched stage were grown in vitro to obtain trophoblast monolayers.

Placental trophoblast. Placentae were recovered from pregnant baboons between Days 31 and 39 of gestation. Tissues were collected aseptically and cells dispersed using the method of Risbridger et al. (1985). Placental tissue was cut into small pieces with scissors and washed thoroughly with ovum culture medium. The cells were allowed to disperse in $0.5 \%$ collagenase (Sigma Chemical Co., St Louis, MO, USA) in ovum culture medium for $30 \mathrm{~min}$ at $37 \mathrm{C}$ in a $5 \% \mathrm{CO}_{2} / 95 \%$ air atmosphere. A further volume of collagenase was added and the cells were redispersed for another two periods of $20 \mathrm{~min}$. The cells were centrifuged at $200 \mathrm{~g}$ for $5 \mathrm{~min}$, washed three times with the ovum culture medium and finally resuspended in Hams Fl0 medium with $20 \%$ (v/v) fetal calf serum, $5.0 \mu \mathrm{g}$ amphotericin B deoxycholate $/ \mathrm{ml}, 100 \mu \mathrm{g}$ gentamycin $/ \mathrm{ml}, 100$ units penicillin $/ \mathrm{ml}$ and $100 \mu \mathrm{g}$ streptomycin/ml (all reagents from Flow Laboratories). An aliquant was removed for counting in a haemocytometer. The cells were then cultured and established in vitro.

Embryo and placental trophoblast culture. The culture medium was Hams F10 (Flow Laboratories) containing $20 \%$ heat-inactivated fetal calf serum and antibiotics in the concentrations given above. Embryos were cultured in flat-bottomed microtitre plate (Falcon 3042) wells in $200 \mu \mathrm{l}$ medium under an atmosphere of $5 \% \mathrm{CO}_{2} / 95 \%$ air at $37^{\circ} \mathrm{C}$. The culture medium was changed daily and the embryo transferred into a fresh well in the same plate using a finely drawn Pasteur pipette under controlled suction. After attachment, the medium was changed daily. Photographs of the embryo were taken daily. Individual spent medium samples were stored at $-20^{\circ} \mathrm{C}$ until required for radioimmunoassay studies.

Trophoblast cells, as identified by their morphology and adherent nature (Zuckermann \& Head, 1986) were cultured in 24-well flat-bottomed plates (Nunclon, Inter Med. Kamstrup, Roskilde, Denmark) containing $1 \mathrm{ml}$ Hams F10 medium supplemented with fetal calf serum and antibiotics as above under an atmosphere of $5 \% \mathrm{CO} / 95 \%$ air at $37^{\circ} \mathrm{C}$. The culture medium was changed daily by withdrawal of medium through a finely drawn Pasteur pipette under controlled suction. Individual spent samples were stored at $-20^{\circ} \mathrm{C}$ until radioimmunoassay. Embryo- and placenta-derived trophoblast tissues were utilized in immunohistochemical studies to localize CG.

Assay of CG. Baboon CG was measured in culture medium using a double-antibody procedure described by Bambra et al. (1984). This assay used a rabbit antiserum against baboon CG (2001-102782) kindly provided by Professor V. Stevens (Department of Obstetrics and Gynecology, Ohio State University, Columbus, OH, USA) and was used at a final dilution of 1:3000. The tracer was ${ }^{125}$ I-labelled hCG prepared at the Institute and the Second International hCG Standard (MRC 61/6, NIBSC, London) was used as the standard material. The sensitivity of the assay $(\mathrm{B} / \mathrm{Bo}=90 \%)$ was $0 \cdot 2 \mathrm{ng} /$ tube. Inter and intra-assay coefficients of variation were $12 \%$ and $7 \cdot 1 \%$ respectively. Protease inhibitor (soybean trypsin inhibitor: Sigma) was incorporated in all assay buffers.

Histochemical studies. Placental sections were deparaffinized in xylene and hydrated. All sections were sequentially incubated for $30 \mathrm{~min}$ at room temperature with each of the following reagents: (1) a solution of $0 \cdot 3 \%(\mathrm{w} / \mathrm{v})$ hydrogen peroxide in methanol to block endogenous peroxidase activity; (2) normal rabbit serum (1:10 dilution) to decrease non-specific background staining; (3) rabbit antiserum against baboon $C G$ as used in the radioimmunoassay (1:20) or hCG (R2001, 1:250) kindly provided by Professor R. Ryan (Department of Cell Biology, Mayo Clinic, Rochester, MN, USA); (4) with diluted biotinylated rabbit antibody (Sigma Chemical Co.); (5) Vectastain ABC reagent (Vector Laboratories, Burlingame, CA, USA). After each incubation the slides were washed with 10 mm-sodium phosphate, $\mathrm{pH} 7 \cdot 5,0.9 \%$ saline. The reaction product of the section was developed with a freshly prepared solution containing 3,3-diaminobenzine tetrahydrochloride ( $50 \mathrm{mg}$ per $100 \mathrm{ml}$ PBS to which was added $0.02 \%$ hydrogen peroxide). Sections were washed with water, counterstained with haematoxylin and mounted in Permount. Hormone antisera and method specificity were tested by substituting an unrelated antibody for the specific antiserum, omitting the antihormone antibody step and absorption of the antibody with the homologous hormone.

Cultures of trophoblast derived from both the placenta and embryo were also subjected to this immunohistochemical method. However, before use the sections were fixed overnight in $70 \%$ alcohol and the incubations with various agents were carried out in the tissue-culture plate wells. After washing with water and counterstaining with haematoxylin the cells were covered with a glycerol-PBS mixture before light microscopy. 


\section{Results}

\section{Radioimmunoassay results}

Both the embryos used in this study were recovered at the hatched blastocyst stage (Fig. 1) and were grown in vitro for up to 13 days (Fig. 2). They secreted measurable quantities of $C G$ as determined by radioimmunoassay (Table 1). The secretion reached peak levels at Day 10 in vitro and continued for the duration of culture. Trophoblast cells were dispersed from the placenta and allowed to grow in vitro for up to 5 days (Fig. 3). They also secreted measurable quantities of CG (Table 2).

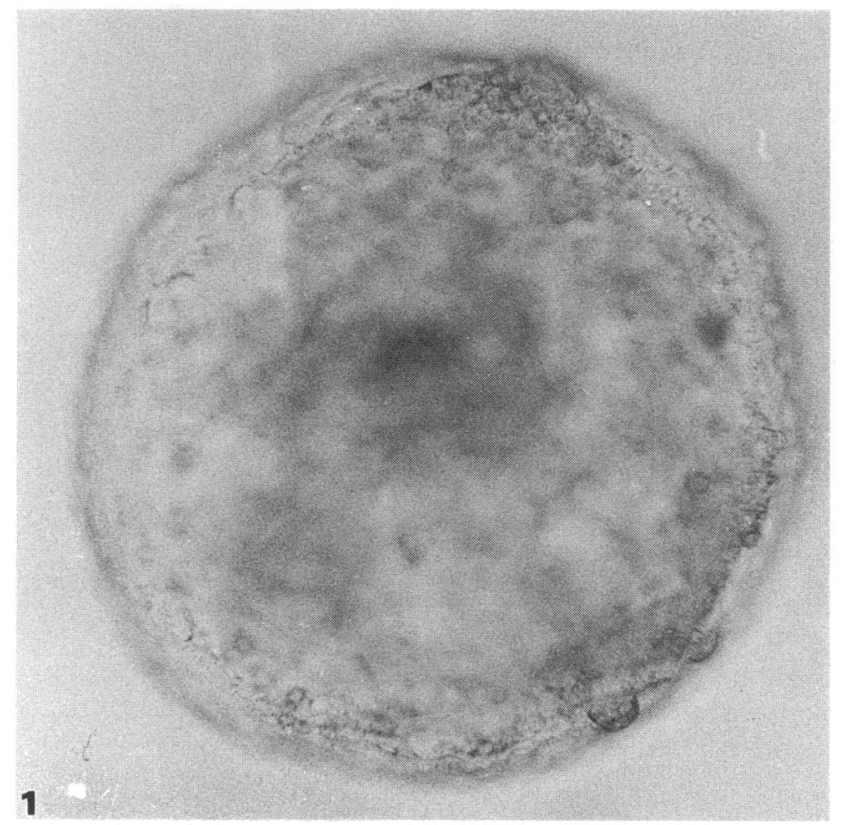

Fig. 1. Hatched blastocyst recovered by non-surgical uterine flushing. $\times 440$.

\section{Immunohistochemical studies}

Placenta. The omission of any one component from the sequential immunoperoxidase method resulted in negative results, as did the use of antiserum which had been previously adsorbed with excess antigen (Fig. 4a). A positive reaction was seen in the villous syncytiotrophoblast with both antiserum to baboon CG (Fig. 4b) and hCG (Fig. 4c); the former antiserum giving the stronger reaction. Cytotrophoblast cells, stroma, endothelia of villous fetal vessels, decidua and endometrial glands gave consistently negative results.

Embryo-derived trophoblast. As in the staining of the placental sections specificity controls gave negative results. A strong positive reaction was obtained with syncytial cells and localization was confined to the cytoplasm (Fig. 5a).

Placenta-derived trophoblast. Once again specificity controls gave negative results. Positive staining was similar to that of the embryo-derived trophoblast in that the positive staining reaction product was restricted to the cytoplasm of trophoblast (Fig. 5b). 

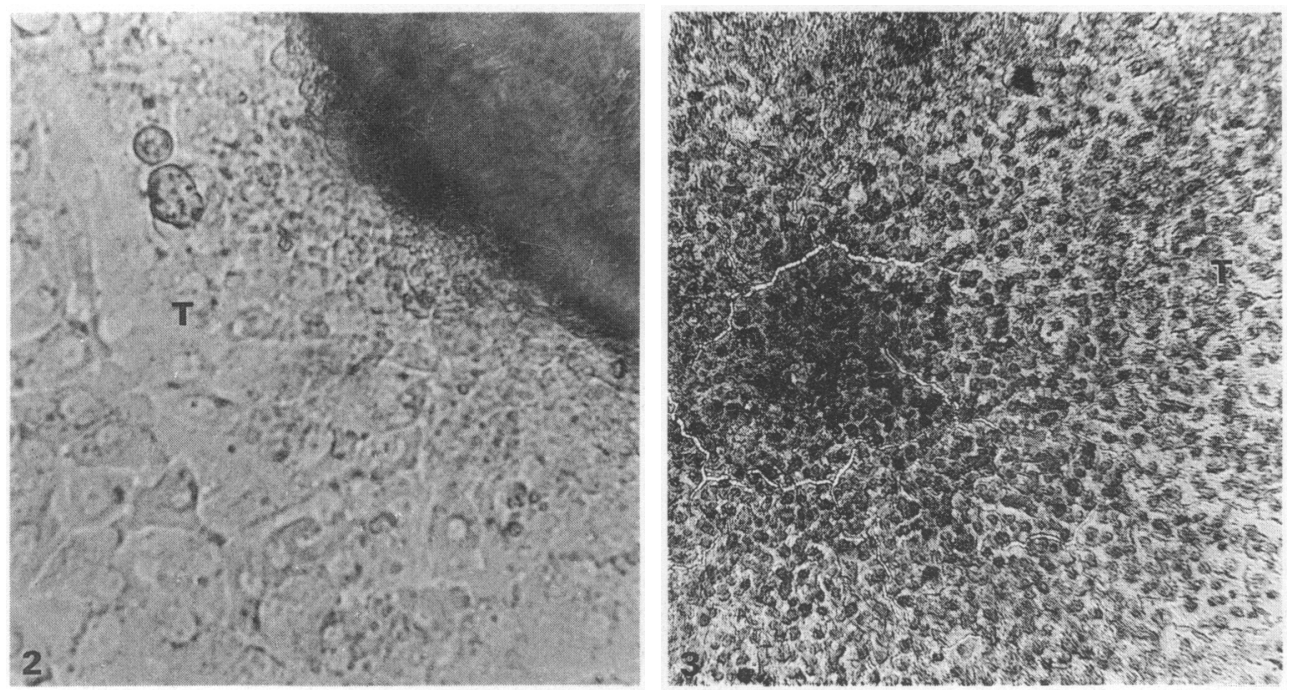

Fig. 2. Attached embryo showing extensive trophoblast outgrowth (T) after 14 days in culture. $\times 440$.

Fig. 3. A photomicrograph of placenta-derived trophoblast showing the appearance of the trophoblast $(\mathrm{T}) . \times 280$.

Table 1. Secretion of CG by 2 baboon embryos

\begin{tabular}{|c|c|c|}
\hline $\begin{array}{l}\text { Day in } \\
\text { culture }\end{array}$ & Developmental stage & $\begin{array}{l}\text { CG production } \\
\text { (i.u.day) }\end{array}$ \\
\hline 1 & Hatched blastocyst & Not measurable \\
\hline 2 & Start of attachment & $\begin{array}{l}0 \cdot 10 \\
0 \cdot 11\end{array}$ \\
\hline 3 & Attachment & $\begin{array}{l}1 \cdot 50 \\
1 \cdot 80\end{array}$ \\
\hline 4 & After attachment & $\begin{array}{l}2 \cdot 10 \\
2 \cdot 80\end{array}$ \\
\hline 5 & After attachment & $\begin{array}{l}2 \cdot 50 \\
3 \cdot 10\end{array}$ \\
\hline 6 & After attachment & $\begin{array}{l}3 \cdot 30 \\
3 \cdot 60\end{array}$ \\
\hline 7 & After attachment & $\begin{array}{l}3 \cdot 50 \\
3 \cdot 70\end{array}$ \\
\hline 8 & After attachment & $\begin{array}{l}3 \cdot 60 \\
3 \cdot 80\end{array}$ \\
\hline 9 & After attachment & $\begin{array}{l}3 \cdot 50 \\
4 \cdot 30\end{array}$ \\
\hline 10 & After attachment & $\begin{array}{l}3 \cdot 90 \\
4 \cdot 50\end{array}$ \\
\hline 11 & After attachment & $\begin{array}{l}3 \cdot 70 \\
4 \cdot 30\end{array}$ \\
\hline 12 & After attachment & $\begin{array}{l}3 \cdot 90 \\
4 \cdot 10\end{array}$ \\
\hline
\end{tabular}


Table 2. Secretion of CG by placental trophoblast cells of baboons

\begin{tabular}{|c|c|c|}
\hline \multirow{2}{*}{$\begin{array}{l}\text { Day in } \\
\text { culture }\end{array}$} & \multicolumn{2}{|c|}{ CG secretion } \\
\hline & i.u./well* & mi.u./placenta \\
\hline 1 & $44.0 \pm 1.0$ & 1056.0 \\
\hline 2 & $33.4 \pm 0.8$ & $801 \cdot 6$ \\
\hline 3 & $31.9 \pm 1.4$ & 765.6 \\
\hline 4 & $27 \cdot 3 \pm 1 \cdot 2$ & $655 \cdot 2$ \\
\hline 5 & $21 \cdot 1 \pm 1 \cdot 3$ & $506 \cdot 4$ \\
\hline
\end{tabular}

*Values are mean \pm s.e.m. for 10 observations.
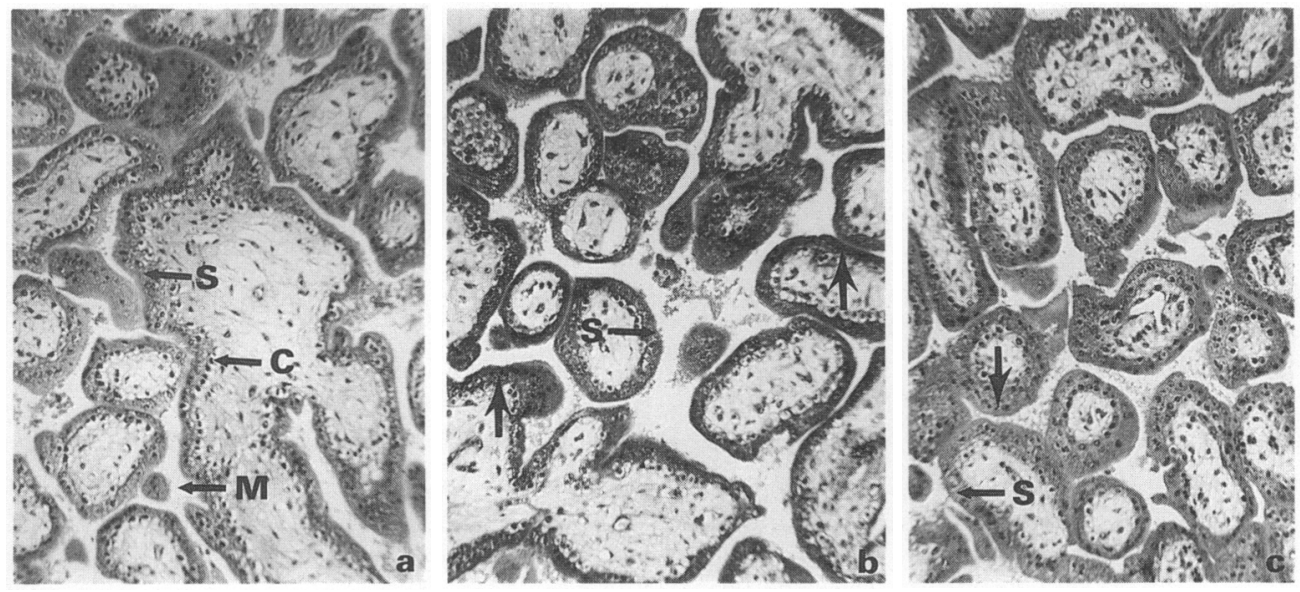

Fig. 4. Photomicrographs of placental sections showing (a) lack of staining due to specificity of the antiserum; (b) a positive reaction (arrow) and localization of CG-like material on the villous syncytiotrophoblast; and (c) a positive reaction (arrow) and localization of hCG-like material on the villous syncytiotrophoblast. $\mathrm{S}=$ syncytiotrophoblast; $\mathrm{C}=$ cytotrophoblast; $\mathrm{M}=$ maternal blood space. $\times 200$.

\section{Discussion}

A previous study has shown that baboon embryos grown in vitro are capable of secreting CG which can be detected by radioimmunoassay (RIA) at or after attachment of the hatched blastocyst to the culture vessel (Pope et al., 1982). Pope et al. (1982) used a heterologous RIA and sheep $\beta$-subunit LH antiserum (H-26); peak secretion of CG occurred 7-12 days after hatching and continued for up to 27 or more days. The assay results obtained with the 2 embryos growing in vitro in the present study are in good agreement with those obtained by Pope et al. (1982). A more specific radioimmunoassay utilizing an anti-baboon CG serum was used and concentrations of baboon CG increased with attachment of the embryos to the culture vessels and tended to reach a peak 7 days after attachment. Moreover, it was apparent that measurable quantities of baboon CG. were produced by the hatched blastocyst before its attachment. The preimplantation human blastocyst is believed to secrete detectable amounts of CG into the blood (Saxena et al., 1974) and CG may be present on the surface of the free blastocyst or its environment (Hearn, 1980). The marmoset also secretes a CG before attachment (J. P. Hearn, S. Gems, J. K. Hodges \& C. Wennink, unpublished data). 

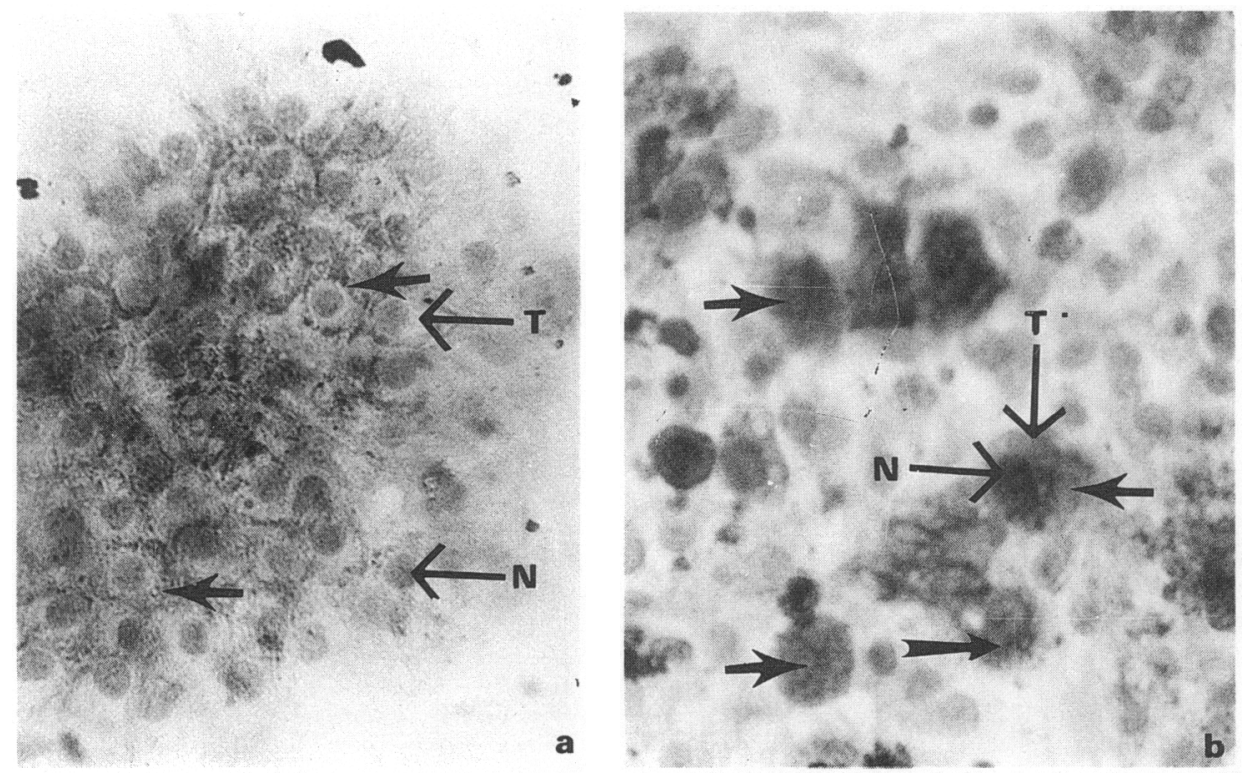

Fig. 5. Positive staining for baboon CG in (a) embryo-derived trophoblast and (b) placentaderived trophoblast. $\mathrm{T}=$ trophoblast cells; $\mathrm{N}=$ nucleus; arrows $=$ reaction product. $\times 440$.

Trophoblast cells derived from human (Tojo et al., 1974; Huot et al., 1979; Kim et al., 1987), marmoset (Summers et al., 1987) and baboon (Pope et al., 1982) embryos and grown in vitro have been reported to secrete $\mathrm{CG}$ as measured by RIA. The present findings confirm the baboon data of Pope et al. (1982) who utilized trophoblast cells derived from 2 embryos and up to 200 mi.u. $\mathrm{CG} /$ day could be measured when the anti-ovine $\mathrm{LH}$ serum was used in RIA. The values obtained in the present study are considerably higher and ranged from 506 to $1056 \mathrm{mi}$.u. CG/day (Table 2). However, the placenta was used as the source of trophoblast cells and these were found to be viable before their utilization in histochemical studies as demonstrated by their histological appearance and continued secretion of CG. As culture time of baboon trophoblast cells increased, the amounts of CG secreted appeared to decline. This has been reported for long-term cultures of human trophoblast; hCG and placental lactogen values were lower than the levels detectable after 10 days in vitro (Nelson et al., 1986).

The CG material detected by RIA in the present study was associated with the syncytiotrophoblast in fixed placental tissue and this is in agreement with reports on localization of hCG in human placenta (see Midgley \& Pearce, 1962; Ikonicoff \& Cedard, 1973; Tabarelli et al., 1983; Al-Timini \& Fox, 1986). When hCG antiserum was used instead of baboon CG antiserum a lower intensity of staining was observed on fixed placental sections. This is consistent with reports that $\beta$-hCG antisera raised in rabbits and baboons reacts with baboon CG but to a substantially lesser extent than with hCG (Stevens, 1976).

The baboon placental or embryonic trophoblast cells grown in vitro were not characterized. It has been reported that most of the embryo- (Pope et al., 1982; Fishel et al., 1984; Summers et al., 1987) or placenta- (Loke et al., 1986; Nelson et al., 1986; Ungar et al., 1987) derived trophoblast cells which establish in culture are cytotrophoblast. It has been shown that hCG is localized on cellular trophoblast in culture (Chung et al., 1969; Fox \& Kharkongor, 1970; Loke et al., 1972; Cotte et al., 1980) and thus localization of hCG on cultured baboon trophoblast cells is not surprising.

Based on the facts that: (1) the antibodies used in this study were specific; (2) the method was specific; (3) no reaction was obtained when the specific antibody was substituted with an unrelated 
one; and (4) there was abolition of staining by prior absorption with the particular antigens, it can be deduced that the immunoperoxidase reaction noted in the present study showed a specific localization. This, considered in conjunction with the RIA results, indicates that the baboon syncytiotrophoblast cells are the probable site of secretion of this material.

In the marmoset, $\mathrm{CG}$ may be an important requirement for attachment and baboon $\mathrm{CG}$ may have a similar role.

We are greatly indebted to the WHO special Programme of Research Training in Human Reproduction for financial support for this study and to Ms Francisca Kinyua for typing this manuscript.

\section{References}

Ahmed, A.G. \& Klopper, A. (1983) Diagnosis of early pregnancy by assay of placental proteins. $\mathrm{Br} . J$. Obstet. Gynaecol. 90, 604-611.

Al-Timini, A. \& Fox, H. (1986) Immunohistochemical localization of follicle-stimulating hormone, luteinizing hormone, growth hormone, adrenocorticotrophic hormone and prolactin in human placenta. Placenta $7,163-172$.

Asch, R.H., Fernades, E.O., Magnasco, L.A. \& Pauerstein, C.J. (1978) Demonstration of a chorionic gonadotrophin-like substance in rabbit morulae. Fert. Steril. 29, 444-449.

Asch, R.H., Fernandes, E.O., Siler-Khodr, T.M. \& Pauerstein, C.J. (1979) Evidence for a human chorionic gonadotrophin-like material in the rabbit blastocyst. Fert. Steril. 32, 697-703.

Bambra, C.S. (1987) Purification and properties of baboon chorionic gonadotrophin. J. Reprod. Fert. 79, $421-430$.

Bambra, C.S., Eley, R.M. \& Wall, H. (1984) Limitations of the non-human pregnancy kit for pregnancy diagnosis in baboons. J. med. Primatol. 13, 219-229.

Batta, S.K. \& Channing, C.P. (1979) Preimplantation rhesus monkey blastocyst: secretion of substance capable of stimulating progesterone secretion by granulosa cells. Life Sci. 25, 2057-2059.

Beck, J.S., Gordon, R.L., Donald, D. \& Melvin, J.M.O. (1969) Immunofluorescent localization of hCG in chorionic villus of man. J. Path. Bact. 97, 545-555.

Catt, K.J., Dufau, M.L. \& Vaitukaitis, J.L. (1975) Appearance of hCG in pregnancy plasma following the initiation of implantation of the blastocyst. $J$. clin. Endor. Metab. 40, 537-540.

Chung, H.K., Melimans, W.F., Horoszewicz, J. \& Hreshchyshyn, M.M. (1969) In vitro studies of human trophoblast. Am. J. Obstet. Gynecol. 104, 945-952.

Cotte, C., Easty, C.G., Neville, A.M. \& Monaghan, P. (1980) Preparation of highly purified cytotrophoblast from human placenta with subsequent modulation to form syncytiotrophoblast in monolayer cultures. In Vitro 16, 639-646.

Fishel, S.B., Edwards, R.G. \& Evans, C.J. (1984) Human chorionic gonadotrophin secreted by preimplantation embryos cultured in vitro. Science, $N Y$ 223, $816-818$.

Fox, H. \& Kharkongor, F.N. (1970) Immunofluorescent localization of chorionic gonadotrophin in the placenta and in tissue cultures of human trophoblast. J. Path. 101, 277-282.
Genabacev, O. \& Sulovic, V. (1975) Localization of human chorionic gonadotrophin by immunohistochemical method in normal and pathological human placenta. Cytobiologie 11, 95-100.

Genabacev, O., Robyn, C. \& Pantic, V. (1972) Localization of chorionic gonadotrophin in human term placenta on ultrathin sections with peroxidase labelled antibody. J. Microscopie 15, 399-402.

Hamanaka, N., Tanazawa, O., Hashimoto, T., Yoshinare, S. \& Okudaira, Y. (1971) Electron microscopic study on the localization of human chorionic (hCG) in the chorionic tissue by enzyme labelled antibody technique. J. elect. Microscop. 20, 128-130.

Haour, F. \& Saxena, B.B. (1974) Detection of a gonadotrophin in rabbit blastocyst before implantation. Science, NY 185, 444445.

Hay, D.L. (1985) Discordant and variable production of human chorionic gonadotrophin and its free $\alpha$ - and $\beta$-subunits in early pregnancy. J. clin. Endocr. Metab. 61, 1195-1200.

Hearn, J.P. (1980) The immunobiology of chorionic gonadotrophin. In Immunological Aspects of Reproduction and Fertility Control, pp. 229-244. Ed. J. P. Hearn. MTP Press, Lancaster.

Hodgen, G.D. (1980) Patterns of secretion and antigenic similarities among primate chorionic gonadotrophins: significance in fertility research. In Chorionic Gonadotrophin, pp. 53-63. Ed. S. J. Segal. Plenum Press, New York.

Huot, R.I., Foidart, J.M. \& Stromberg, K. (1979) Effects of culture conditions on the synthesis of human chorionic gonadotrophin by placental organ culture. In Vitro 15, 497-502.

Ikonicoff, L.K. \& Cedard, L. (1973) Localization of human chorionic gonadotrophin and somatomammotrophin hormones by the peroxidase immunohistoenzymologic method in villi and amniotic epithelium of human placentas (from six weeks to term). Am.J. Obstet. Gynecol. 116, 1124-1132.

Kim, S.J., Namkoong, J.W., Lee, J.W., Jung, J.K., Kang, B.C. \& Park, J.S. (1987) Response of human chorionic gonadotrophin to luteinizing hormone releasing hormone stimulation in the culture media of normal human placenta, chorio-carcinoma cell lines and in the serum of patients with gestational trophoblastic disease. Placenta 8, 257-264.

Landesman, R. \& Saxena, B.B. (1976) Results of the first 1000 radioreceptor assays for the determination of human chorionic gonadotrophin. Fert. Steril. 27, 357-361. 
Loke, Y.W., Wilson, D.V. \& Borland, R. (1972) Localization of human chorionic gonadotrophin in monolayer of trophoblast cells by mixed agglutination. Am. J. Obstet. Gynecol. 113, 875-879.

Loke, Y.W., Butterworth, B.H., Margetts, J.J. \& Burland, K. (1986) Identification of cytotrophoblast colonies in cultures of human placental cells using monoclonal antibodies. Placenta 7, 221-231.

Midgley, A.R. \& Pierce, G.B. (1962) Immunohistochemical localization of human chorionic gonadotrophin. J. exp. Med. 115, 289-291.

Nelson, M.D., Meister, R.K., Ortman-Nabi, J., Sparks, S. \& Stevens, V.C. (1986) Differentiation and secretory activities of cultured human placental cytotrophoblast. Placenta 7, 1-16.

Pope, C.E., Pope, V.Z. \& Beck, L.R. (1980) Nonsurgical recovery of uterine embryos in the baboon. Biol. Reprod. 23, 657-662.

Pope, V.Z., Pope, C.E. \& Beck, L.R. (1982) Gonadotrophin production by the baboon embryo in vitro. In In Vitro Fertilization and Embryo Transfer, pp. 129-134. Eds E. S. E. Hafez \& K. Semm. MTP Press, Lancaster.

Risbridger, G.P., Harper, C.M.L., Wong, M.H. \& Thorburn, G.D. (1985) Gestational changes in prostaglandin production by ovine fetal trophoblast cells. Placenta 6, 117-126.

Saxena, B.B., Hasan, S.H., Haour, F. \& SchmidtGollwitzer, M. (1974) Radioreceptor assay of human chorionic gonadotrophin: detection of early pregnancy. Science, $N Y$ 184, 793-795.

Stevens, V.C. (1976) Antifertility effects from immunizations with intact, subunits and fragments of HCG. In Physiological Effects of Immunity against Reproductive Hormones, pp. 249-274. Eds R. G. Edwards \& M. H. Johnson. Cambridge University Press.
Summers, P.M., Taylor, C.T. \& Hearn, J.P. (1987) Characteristics of trophoblastic tissue derived from in vitro culture of preimplantation embryos of the common marmoset monkey. Placenta $\mathbf{8}$, $411-422$.

Tabarelli, M., Kofler, R. \& Wick, G. (1983) Placental hormones: 1. Immunofluorescence studies of the localization of chorionic gonadotrophin, placental lactogen and prolactin in human and rat placenta and in the endometrium of pregnant rats. Placenta 4, 379-388.

Thiede, H.A. \& Choate, J.W. (1963) Immunofluorescent examination of the human chorionic villus for blood group A and B substance. J. exp. Med. 121, 1039-1041.

Tojo, S., Mochizuki, M. \& Maruo, T. (1974) Chorionic gonadotrophin produced from the cultivated trophoblast. In Gonadotrophins and Gonadal Function, pp. 321-331. Ed. N. R. Moudgal. Academic Press, New York.

Ungar, L., Csonka, E., Kazy, Z., Siklos, P. \& Hercz, P. (1987) The use of pregnancy serum to obtain trophoblastic cell cultures. Placenta 8, 639-646.

Varma, S.K., Dawood, M.Y., Hapir, F., Channing, C. \& Saxena, B.B. (1979) Gonadotrophin-like substance in the pre-implanted rabbit blastocyst. Fert. Steril. 312, $68-75$.

Wiley, L.D. (1974) Presence of a gonadotrophin on the surface of preimplanted mouse embryos. Nature, Lond. 252, 715-716.

Zuckermann, F.A. \& Head, J.R. (1986) Isolation and characterization of trophoblast from murine placenta. Placenta 7, 349-364.

Received 14 July 1989 